\title{
An assessment of mental health status of physicians working in medical college hospitals of Dhaka city
}

\author{
Kazi Mahbubul Haque, ${ }^{1}$ Md Shafiqul Islam, ${ }^{2}$ Saida Sharmin ${ }^{3}$ \\ ${ }^{1}$ Lecturer, Department of Community Medicine, Shaheed Monsur Ali Medical College, Uttara, Dhaka, Bangladesh; ${ }^{2}$ Professor, \\ Former Head of the Department of Epidemiology, NIPSOM, Mohakhali, Dhaka, Bangladesh; ${ }^{3}$ Assistant Professor, Department of \\ Community Medicine International Medical College, Tongi, Gazipur, Bangladesh.
}

$\begin{array}{ll}\text { Article info } & \\ \text { Received } & : 13 \mathrm{Nov}, 2020 \\ \text { Accepted } & : 02 \mathrm{Feb}, 2020 \\ \text { Number of tables } & : 03 \\ \text { Number of figures } & : 00 \\ \text { Number of refs } & : 12\end{array}$

\section{Correspondence}

Kazi Mahbubul Haque

Mobile: +8801715279685

E-mail:dr.kmh13@outlook.com

\section{Summary}

Mental health status is often ignored in our country. Even many health care professionals commonly ignore the impact of mental illness on both daily and professional lives, which may lead to dire consequences. The purpose of this study was to find the mental health status of physicians working in medical college hospitals of Dhaka city. A cross sectional study was conducted from January to December 2015 for this purpose among 215 number of respondents selected conveniently. Data were collected from 210 physicians by face-to face interview using a semi structured questionnaire containing 4DSQ (Four-Dimensional Symptom Questionnaire), socio economic and other variables. The prevalence of mental illness was calculated according to the scoring system of the scale. Mental illness prevalence was as follows: distress $20 \%$, Anxiety $15.7 \%$, Depression $15.2 \%$ and Somatization $8.6 \%$. Majority of the respondents were interns and below 30 years of age. However, in light of current pandemic situation, regular assessment of health personnel's mental health is needed more than ever.

Bang J Psychiatry 2018;32(2): 37-39

\section{Introduction}

Mental health is a positive state in which one is responsible, displays self-awareness, is self-directive, reasonably worry free and can cope with usual daily tensions. Such individuals are accepted with in a group and function well in society and generally satisfied with their life; able to solve problems, cope with crisis, maintain a state of well-being by enjoying life, setting goals and realistic limits, becoming independent, interdependent or dependent as the need arises without permanently losing one's independence ${ }^{1}$. Physicians working in health facilities are exposed to heavy workload, consisting but not limited to professionalism, responsibility, maintaining patient doctor relationship ${ }^{2}$. Also, they often have to work with limited support from the adminstration ${ }^{3}$. Working in stressful environment in turn affects health, both physical and mental ${ }^{4}$. Unfortunately, studies and investigations about mental health usually remains underestimated, it occurs due to various reasons. Unlike physical illness; where the patient mainly suffers from disease, one suffering from mental health illness also carry the burden of a mark of disgrace associated with a particular circumstance, quality, or person which is known as stigma. Many people with serious mental illness are challenged doubly. On one hand, they struggle with the symptoms and disabilities that result from the disease. On the other, they are challenged by the stereotypes and prejudice that result from misconceptions about mental illness. The impact of stigma is twofold, as patients of mental illness also have to deal with public stigma. Public stigma is the reaction that the general population has to people with mental illness. Self-stigma is the prejudice which people with mental illness turn against themselves ${ }^{5}$. Although stigmatizing attitudes are not limited to mental illness, the public seems to disapprove persons with psychiatric disabilities significantly more than persons with related conditions such as physical illness ${ }^{6}$. Even well-trained professionals from most mental health disciplines subscribe to stereotypes about mental illness ${ }^{7}$. Also, physicians seem to decidedly reluctant to address depression, a significant cause of morbidity and mortality that disproportionately affects them ${ }^{8}$. In such contexts, the purpose of this study was to assess the mental health status of physicians working in medical college hospitals.

\section{Materials and methods}

This was a cross sectional study. Study population consisted of physicians working in nine different medical colleges of Dhaka city. The establishments were MARKS Medical College, Delta Medical College, Greenlife Medical College, Dhaka Central International Medical College, Popular Medical College Hospital, Northern International Medical College, Shaheed Monsur Ali Medical College, Shahabuddin Medical College and UttaraAdhunik Medical College. This study was conducted during a period of 
12 months from January to December 2015. A total of 210 physicians were selected fulfilling the inclusion and exclusion criteria. Physicians from the clinical section of medical colleges were selected. Physicians from academic section and honorary physicians were excluded. Sampling and study place were according to convenient sampling technique. Their mental health was assessed using self-administered questionnaire developed from Four-Dimensional Symptom Questionnaire (4DSQ) ${ }^{8}$, a scale developed to determine depression, distress, anxiety and somatization using self-administered questionnaire. Socio economic and occupational information were also collected. Categorization of data were done where it was needed. SPSS were used for the statistical purposes.

\section{Results}

The results showed that the age of majority of the respondents were below 30 (81.9\%). Study population comprised of 115 male and 95 female respondents. Majority of the respondents were Muslims (91\%) and unmarried (68\%), which was expected considering their young age. Nearly half $(52.4 \%)$ of the respondent's monthly expenditure were ranged between 10000 taka to 30000 taka.

Table 1: Distribution of the respondents according to socio-economic characteristics $(n=210)$

\begin{tabular}{lcc}
\hline Characteristics & Number & Percentage \\
\hline Age (Years) & 172 & 81.9 \\
$<30$ & 38 & 18.1 \\
$\geq 30$ & & \\
Sex & 115 & 54.8 \\
Male & 95 & 45.2 \\
Female & & \\
Religion & 191 & 91 \\
Muslim & 19 & 9 \\
Non-Muslim & & \\
Marital status & 143 & 68 \\
Unmarried & 67 & 32 \\
Married & & \\
Monthly expenditure & 74 & 35.2 \\
$\leq 10000$ taka & 110 & 52.4 \\
$>10000$ taka-30000 taka & 26 & 12.4 \\
$>30000$ taka & & \\
\hline
\end{tabular}

Occupational characteristics revealed that most of the respondents were interns (61.9\%). Nearly half were satisfied with their salary $(45 \%)$ and never experienced conflicts with their colleagues (53.8\%). A good number of respondents occasionally to usually experienced high workload $(77.1 \%)$ and lack of job recognition (64.3\%).
Table 2: Distribution of the respondents according to occupational characteristics $(n=210)$

\begin{tabular}{lcc}
\hline Characteristics & Number & Percentage \\
\hline Designated post & & \\
Interns & 130 & 61.9 \\
Permanent physicians & 80 & 38.1 \\
Salary dissatisfaction & & \\
Never & 45 & 21.4 \\
Occasionally & 65 & 31 \\
Often & 39 & 18.5 \\
usually & 23 & 11 \\
Very often & 38 & 18.1 \\
Conflict with coworkers & & \\
Never & 113 & 53.8 \\
Occasionally & 75 & 35.7 \\
Often & 11 & 5.2 \\
usually & 5 & 2.4 \\
Very often & 6 & 2.9 \\
Experiencing high workload & & \\
Never & 26 & 12.4 \\
Occasionally & 63 & 30 \\
Often & 56 & 26.6 \\
usually & 43 & 20.5 \\
Very often & 22 & 10.5 \\
Lack of job recognition & & \\
Never & 50 & 23.8 \\
Occasionally & 55 & 26.2 \\
Often & 49.3 \\
usually & 31 & 14.8 \\
Very often & 25 & \\
Mental health status of the respondents & \\
\hline
\end{tabular}

Mental health status of the respondents was measured by using the $4 \mathrm{DSQ}$, which is used to assess the level of distress, depression, anxiety and somatization. It measured the conditions as absent, moderately elevated and strongly elevated by summing up the scores from the answers. Mental health status showed that distress was highest $(20 \%)$, followed by anxiety $(15.7 \%)$ and depression (15.2\%). Somatization were lowest (8.6\%) among the respondents.

Table 3: Mental health status of the respondents $(n=210)$

\begin{tabular}{lcc}
\hline Characteristics & Number & Percentage \\
\hline Level of distress & & \\
Strongly elevated & 9 & 4.3 \\
Moderately elevated & 33 & 15.7 \\
No elevation & 168 & 80 \\
Level of anxiety & & \\
Strongly elevated & 12 & 5.7 \\
Moderately elevated & 21 & 10 \\
No elevation & 177 & 84.3 \\
Level of depression & & \\
Strongly elevated & 15 & 7.1 \\
Moderately elevated & 17 & 8.1 \\
No elevation & 178 & 84.8 \\
Level of somatization & & \\
Strongly elevated & 4 & 1.9 \\
Moderately elevated & 16 & 6.7 \\
No elevation & 192 & 91.4 \\
\hline
\end{tabular}




\section{Discussion}

The 4DSQ was used to assess the mental health status of the respondents. The scale consists of 50 items which is used to assess the level of depression, distress, anxiety and somatization. The answer for each item ranges from 0 to 2 . The scores of the items are summed up for determining any of the before mentioned conditions. One item can be used to determine one condition only. Mental health status was found mostly in healthy state. However, this study was conducted on medical college hospitals and the respondents were mainly interns who did not go through as much stressful conditions as the permanent physicians due to their short tenure as physicians. Another study in 2016 involving physicians and other hospital staff yielded rather alarming results ${ }^{10}$ as $86.2 \%$ of the physicians were found moderately stressful $11.7 \%$ were found very stressful in their work, which in total almost consists of the entire doctor population. A study ${ }^{11}$ during COVID-19 pandemic showed that about half of the responding otolaryngology physicians were suffering from Anxiety, distress, burnout, and depression in 167 (47.9\%), 210 (60.2\%), 76 (21.8\%), and 37 (10.6\%) respectively. The variations of the results in different studies could be attributed to factors such as age, designated post, sex, experience, emergency situation, support from authority which differs from institute to institute. Moreover, the emergence of COVID-19 affected the mental health status of the health personnel. As a result, recent study ${ }^{11}$ showed worse outcomes compared to this study although they were both performed in medical college of Dhaka city. Stigma about mental health also plays a major role in revealing the real state. Stigma leads a mentally ill person to cope by concealing their illness, which may ultimately result in suicidal tendencies ${ }^{12}$.

\section{Conclusion}

To find out the mental health status of physicians working in medical college hospitals and its association with their selfreported work ability, this cross-sectional study was conducted. The results showed the mental health status of the physicians. Majority of the physicians did not suffer from distress, depression, anxiety and somatization. Among the four conditions of mental health, distress was most common. The number of physicians with depression and anxiety was almost same. Somatization was least common. As mental health assessment of physicians are still relatively low, further studies are needed to assess the situation properly.

\section{References}

1. Shives LR. Basic Concepts of Psychiatric-Mental Health Nursing. 6th ed. Lippincott Williams \& Wilkins; 2004. p. 7.

2. Tomioka K, Morita N, Saeki K, Okamoto N and Kurumatani N. Working hours, occupational stress and depression among physicians. Occup Med (Lond) [serial online] 2011 May [cited 2015 Nov 1]; 61(3):163-70. Available from: URL: https://academic.oup.com/occmed/ article/61/3/163/1510560

3. Eleni M, Fotini A, Maria M et al. Research in occupational stress among nursing staff- A comparative study in capital and regional hospitals. HJNS [serial online] 2010 Jan [cited 2015 Nov 1]; 3(3):79-84. Available from: URL:https://www.researchgate.net/ publication/ 223736256_Research_in_occupational_stress_among_nursing_staff__a_comparative_study_in_capital_and_regional_hospitals

4. Colligan TW and Higgins EM. Workplace stress-etiology and consequences. J Workplace Behav Health [serial online] 2005 [cited 2015 Nov 2]; 21(2):89-97. Available from: URL:https://www. google.com/url?sa=

t\&rct $=\mathrm{j} \& \mathrm{q}=\&$ esrc $=\mathrm{s} \&$ source $=$ web\&cd $=\&$ ved $=2 \mathrm{ahUKE}$ wiBvl_a_rns AhVxIEsFHZ3bBTo QFjABegQIBh AC\&url= https $\%$ 3A\%2F\%2Fciteseerx. ist.psu.edu $\%$ 2Fviewdoc\% 2Fdownload\% 3Fdoi\%3D10.1.1.464.3414\% 26rep\% 3Drep1\% 26type\%3Dpdf\& usg=AOvVaw0VgXSHOlz FTKZDwQ7YCMFb\& cshid=1602881583904425

5. Corrigan PW and Watson AC. Understanding the impact of stigma on people with mental illness. World Psychiatry [serial online] 2014 Oct [cited 2015 Nov 2]; 15(2):37-70. Available from: URL: https://pubmed.ncbi.nlm.nih.gov/ 26171956/

6. Weiner B, Perry RP and Magnusson J. An attributional analysis of reactions to stigmas. J Pers Soc Psychol [serial online] 1988 Nov [cited 2015 Nov 2]; 55(5):738-48. Available from: URL: https://www.researchgate.net/ publication/

20181145_An_Attribution_Analysis_of_Reactions_to_Stigmas/ link/54e6830f0cf2bff5a 4 f5ffdc/download

7. Patel M. Attitudes to psychosis: Health professionals. Epidemiol Psichiatr Soc [serial online] 2004 Dec [cited 2015 Nov 2]; 13(4):213-8. Available from: URL: https:// www.researchgate.net/publication/ 8041555_Attitudes_to_psychosis_Health_professionals

8. Petersen M R and Burnett C A. The suicide mortality of working physicians and dentists. Occup Med (Lond) [serial online] 2008 Jan [cited 2015 Nov 2]; 58(1):25-9. Available from: URL: https://academic.oup.com/occmed/ article/58/1/25/1536620

9. Terluin B. Four-dimensional symptom questionnaire. MIDSS [serial online] 2012 [cited 2015 Dec 10]; Available from: URL: https://www.midss.org/content/fourdimensional-symptom-questionnaire-4dsq

10. Munir UR, Rahman MF \& Ahsan MA. Occupational Stress in Health Professionals of Combined Military Hospitals. JAFMC Bangladesh [serial online] 2017 Jun [cited 2018 Jan 5]; 13(1): 37-41. Available from: URL: https://www.banglajol.info/index.php/JAFMC/article/view/ 41021

11. Civantos AM, Byrnes Y, Chang C, Prasad A, Chorath K, Poonia SK et al. Mental health among otolaryngology resident and attending physicians during the COVID 19 pandemic: National study. Head Neck [serial online] 2020 Jul [cited 2020 Dec 20]; 42(7): 1597- 1609. Available from: URL: https://onlinelibrary.wiley.com/doi/full/ 10.1002/hed.26292

12. Oexle N, Ajdacic-Gross V, Kilian R, Müller M, Rodgers S, $\mathrm{Xu} Z$ et al. Mental illness stigma, secrecy and suicidal ideation. Epidemiol Psychiatr Sci [serial online] 2017 Feb [ cited 2020 Dec 20]; 26(1): 53-60. Available from: URL: https://pubmed.ncbi.nlm.nih.gov/26606884/ 